\title{
Influência da organização de catadores de materiais recicláveis em associação para a melhoria da saúde e minimização de impactos socioambientais
}

\author{
Influence of organization of recyclable material collectors in association to improve the health and minimization \\ of social-environmental impacts
}

\section{Lívia Poliana Santana Cavalcante' e Monica Maria Pereira da Silva²}

\author{
'Mestre em Recursos Naturais, Programa de Pós-graduação em Recursos Naturais - PPGRN, Universidade Federal de Campina Grande - \\ UFCG, Campina Grande, PB, Brasil
}

${ }^{2}$ Doutora em Recursos Naturais, Departamento de Biologia, Universidade Estadual da Paraíba, Campina Grande, PB, Brasil

\begin{abstract}
Resumo
Este trabalho tem como objetivo avaliar a influência da organização de catadores de materiais recicláveis em associação para a melhoria da saúde e minimização de impactos socioambientais, em Campina Grande - PB. A pesquisa participante foi realizada de agosto de 2010 a novembro de 2011 com 16 catadores de materiais recicláveis, sendo oito associados, e oito que atuam na informalidade em Campina Grande-PB. Os dados foram coletados por meio de encontros semanais, seminários, questionários semiestruturados, acompanhamento socioambiental e econômico dos catadores de materiais recicláveis e analisados de forma qualitativa e quantitativa, sendo os quantitativos, distribuídos em categorias e posteriormente, avaliados em métodos estatísticos em planilhas do Excel. Constatamos que a organização de catadores de materiais recicláveis favoreceu de forma significativa as condições de saúde desses trabalhadores e de sua família, minimizando impactos socioambientais, além de favorecer a coleta seletiva nos bairros de atuação do grupo. Portanto, há influência na organização de catadores de materiais recicláveis em associação para a melhoria da saúde e minimização dos impactos socioambientais, embora no momento desta pesquisa a influência percebida expressasse pequenos avanços em decorrência do pouco tempo de formalização.
\end{abstract}

Palavras-chaves: Catadores de materiais recicláveis. Organização. Saúde.

\begin{abstract}
This study aims to evaluate the influence of the organization of recyclable material collectors in Association to improve the health and minimization of environmental impacts in Campina Grande - PB. The participant survey was conducted from August 2010 to November 2011 with 16 recyclable material collectors, eight members and eight that operate informally in Campina Grande-PB. Data were collected through weekly meetings, seminars, semi-structured questionnaires, environmental and economic monitoring of recyclable material collectors and analyzed qualitatively and quantitatively and the quantitative spread into categories and subsequently evaluated in statistical methods in excel spreadsheets. We note that the organization of recyclable material collectors favored significantly the health conditions of these workers and their families, minimizing environmental impacts, and favor the selective collection in the group's action neighborhoods. So there influence on the organization of recyclable material collectors in association to improve the health and minimization of environmental impacts, although at the time of this research the influence perceived expressed small advances, due to the short time of formalization.
\end{abstract}

Keywords: Recyclable material collectors. Organization. Health. 


\section{INTRODUÇÃO}

A questão ambiental, com sua complexidade, emerge no último terço do século XX como problemáticas contemporâneas, compartilhando o sintoma de uma crise de civilização (LEFF, 2006). Nesse sentido, consideramos que a produção demasiada de resíduos sólidos emerge nesse cenário, nos quais a produção e o consumo exacerbados estão a todo vapor, acarretando diferentes impactos negativos socioambientais e de saúde pública, comprometendo a capacidade de suporte dos diferentes sistemas e a qualidade de vida das futuras e atuais gerações.

De acordo com Porto (2005), a crise ambiental contemporânea vem intensificando as discussões e a percepção pública acerca dos efeitos dos processos de produção e consumo das sociedades industriais pós-modernas sobre a saúde humana e a dos ecossistemas.

Em detrimento dessa crise generalizada, o processo de exclusão social tornou-se apenas um dos seus resultados, acometendo a população menos favorecida, para qual coletar resíduos sólidos tornou-se uma alternativa de sobrevivência (BOFF, 1999; 2003).

A falta de gestão dos resíduos sólidos tem ocasionado impactos negativos ao meio ambiente por provocar danos ao solo, ao ar e às águas superficiais, carregando agentes poluentes presentes nos resíduos, os quais infiltram no solo e podem atingir as águas subterrâneas (AVELAR, 2006). Além de prejudicar diretamente a saúde daquelas populações que sobrevivem ou moram próximo a lixões. Logo, percebemos a importância e a urgência da implantação de políticas públicas municipais voltadas para questões ambientais, em especial para os resíduos sólidos.

Segundo Vieira et al. (2002), em meio aos problemas que acometem a questão dos resíduos sólidos urbanos, surge a atividade do catador de materiais recicláveis, uma parcela da população que excluída socialmente, encontra nos resíduos sólidos a sua única alternativa de sobrevivência. A catação não é apenas um sintoma da crise econômica, é também uma opção comumente forçada de vida para milhares de brasileiros.

A atividade laboral que insurgiu deste contexto ocupa a incoerência do sistema social que a produziu, pois ao mesmo tempo em que o trabalho de catação possibilita a geração de renda própria ao indivíduo, diminuindo sua dependência de ações caridosas, esse profissional sofre o preconceito da população, dada as condições precárias que envolvem o seu trabalho (FILARDI et al., 2011).

Segundo dados do Compromisso Empresarial para Reciclagem (CEMPRE, 2010), o número de pessoas sobrevivendo através da catação de resíduos sólidos na informalidade e organizados ultrapassa a 1.000 .000 de profissionais. Apenas $10 \%$ dos catadores de materiais recicláveis estão melhor organizados, sem a dependência dos intermediários, ou seja, aqueles que trabalham em galpões de reciclagem, mais equipados e com melhor infraestrutura, principalmente sob a forma de cooperativas. Vale salientar que não existe consenso na literatura sobre o número de catadores e catadoras de materiais recicláveis que atua no Brasil, contudo, dados da $4^{a}$ Conferência Nacional do Meio Ambiente mostram que 600 mil pessoas realizam a catação dos resíduos sólidos no país. Deste total, cerca de 60 mil catadores e catadoras de materiais recicláveis atuam junto às cooperativas, demonstrando que a maioria desenvolve seu ofício na informalidade (BRASIL, 2013).

A organização dos catadores em associações ou cooperativas configura-se em uma alternativa de fortalecimento desses profissionais em busca de melhoria de condições de trabalho, com estruturas físicas mais adequadas e oportunidades de ganhos econômicos, sociais, ambientais e de saúde pública. Entretanto, requer o processo de Educação Ambiental para a organização e valorização desses profissionais e para que as famílias adquiram o hábito de dispor seus resíduos sólidos à porta, previamente selecionados (SILVA et al., 2010; 2012).

O cotidiano dos profissionais que vivem da reciclagem dos resíduos sólidos é pouco trabalhado pela saúde pública brasileira (PORTO et al., 2004). Ainda são limitadas as pesquisas que relacionam os riscos à saúde pública e seus efeitos na atividade de catação, mas acidentes com cortes, perfurações, queimaduras, doenças da pele e mucosas são consequências desse contato, além de alta incidência de intoxicações alimentares e doenças parasitárias (SIQUEIRA; MORAIS, 2009). Além dos riscos que os catadores de materiais recicláveis sofrem de contrair doenças infectocontagiosas como a AIDS e Hepatites virais (SIQUEIRA; MORAIS, 2009; PORTO et al., 2004; DALL'AGNOL; FERNANDES, 2007; ALBIZU et al., 2008), que podem estar presentes nos resíduos sólidos de serviço de saúde, visto que uma parte desses resíduos não possui tratamentos prévios, sendo encaminhada diretamente para 
lixões ou aterros sanitários.

A prevalência de alguns sintomas devido a sobrecargas no trabalho desempenhado pelo catador de material reciclável é relatada em diferentes estudos (ALENCAR; CARDOSO; ANTUNES, 2009, LIPP, 2007; MARRAS, 2000). Dentre os sintomas encontrados nas pesquisas de Alencar et al. (2009), podemos destacar dores musculares-esqueléticas, sendo a região mais afetada a região lombar, cansaço físico, dores de cabeça, erupções cutâneas, indigestão, gastrite, insônia, dificuldade em se concentrar, oscilação de humor. De acordo com Alencar et al. (2007), o fato da região lombar ter sido a mais acometida condiz com a maneira que o trabalho é realizado nas ruas e ao longo de jornadas que sobrepõem muitas vezes oito horas de trabalho. Segundo Marras (2000), são fatores de risco para lombalgias os movimentos repetitivos de inclinações e rotações do tronco, e Lipp (2007) cita como sintomas estressores na área emocional depressão, desânimo, raiva, irritabilidade e ansiedade, entre outros.Nesse sentido, este trabalho tem como objetivo avaliar a influência da organização de catadores de materiais recicláveis em associação para a melhoria da saúde e minimização de impactos socioambientais em Campina Grande - PB.

\section{METODOLOGIA}

O presente trabalho foi desenvolvido na Comunidade Nossa Senhora Aparecida no Bairro do Tambor, em Campina Grande - PB.

A Comunidade Nossa Senhora Aparecida originou-se a partir de uma invasão localizada na Zona Sul. Nesta localidade estão inseridos os catadores de materiais recicláveis associados à ARENSA (Associação de Catadores de Materiais Recicláveis da Comunidade Nossa Senhora Aparecida), como também um número significativo de catadores de materiais recicláveis que trabalham na informalidade.

A cidade de Campina Grande possui uma população de 383.941 habitantes (BRASIL, 2010) e

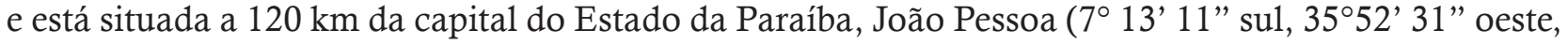
a 550m acima do nível do mar).

O trabalho consiste em uma pesquisa participante, que, de acordo com Thiollent (2008), envolve o processo de investigação, educação e ação, com a participação conjunta de pesquisadores e pesquisados, sendo o principal objetivo da pesquisa a transformação social.

O trabalho foi realizado de agosto de 2010 a julho de 2011 com oito catadores de materiais recicláveis associados à ARENSA, que residem no bairro do Tambor, Campina Grande-PB, e oito catadores de materiais recicláveis que atuam na informalidade e residem no mesmo bairro. Estes foram identificados, cadastrados e motivados a participar do presente projeto. Os dois grupos sociais foram escolhidos a fim de comparar as condições socioambientais a que estão submetidos e analisar as melhorias de qualidade de vida, profissional, social, econômica e de saúde, obtidos pelos catadores de materiais recicláveis associados à ARENSA após a sua organização e formalização.

A ARENSA foi escolhida principalmente pelo seu rápido crescimento econômico, social e profissional, fruto de intenso processo de formação e mobilização social realizado por Silva (2012), Ribeiro et al. (2011) e Cavalcante et al. (2012).

Através da observação direta, questionários semiestruturados e registro fotográfico, foram identificadas as condições socioambientais, econômicas e de saúde a que estão submetidos os catadores de materiais recicláveis associados e informais, analisando a relação entre saúde do catador de material reciclável e a organização do grupo, as condições de moradia, o uso de equipamento proteção individual durante as atividades de catação, acondicionamento e venda dos resíduos sólidos, condições de higiene individual e coletiva (casa, entorno e ambiente de trabalho) e condições de saúde.

Os dados foram analisados de forma quantitativa e qualitativa, utilizando-se da triangulação, que, segundo Thiollent (2008), consiste em quantificar, qualificar e descrever os dados obtidos.

\section{RESULTADOS E DISCUSSÃO}

De acordo com a pesquisa executada, observamos entre os catadores de materiais recicláveis associados à ARENSA e informais a prevalência de idades entre 31 e 40 anos (25,0 \%) e entre 51 e 60 
anos (25,0\%). Embora a faixa etária seja ampla, variando entre 16 e 61 anos de idade.

Verificamos a divergência nas faixas etárias entre os catadores de materiais associados e informais, especialmente na faixa entre 16 e 19 anos (desvio padrão=17,7), o que implica diretamente nas condições de trabalho e saúde. Nesse aspecto, entendemos que os mais jovens possuem mais habilidade e conseguem percorrer distâncias maiores, obtendo mais materiais recicláveis. Outro indicativo é a falta de oportunidade no mercado de trabalho, pois a maioria dos catadores de materiais recicláveis não completou o ensino fundamental.

Em relação ao gênero, averiguamos a participação igualitária de catadores e catadoras de materiais recicláveis, $50,0 \%$ e $50,0 \%$, respectivamente.

Albizu, Lima e Piaskowy (2008) relatam em seu trabalho que há predominânciade catadoras nas centrais de triagem, e, nas coletas realizadas nas ruas, predomina o trabalhador do gênero masculino. Todos os catadores e catadoras de materiais recicláveis que participaram desse trabalho executam a atividade de coleta em rua e de triagem.

Sobral, Santiago e Costa (2009) afirmam que para as mulheres as dificuldades no exercício da catação são ainda mais intensas, uma vez que são responsáveis pela realização de funções estabelecidas socialmente como do gênero feminino, obrigando-as geralmente a exercer a atividade de catação levando seus filhos e tendo que adaptar sua jornada de trabalho nas ruas à jornada de trabalhos no âmbito familiar.

A rotina de trabalho dos catadores de materiais recicláveis associados ocorre sempre em duplas, um homem e uma mulher. O homem possui a função de conduzir os veículos de tração manual e/ ou animal. As mulheres são responsáveis pela coleta dos resíduos sólidos de porta em porta, algumas vezes não encontram os materiais segregados na fonte geradora, sendo necessário que abram as sacolas depositadas em frente às residências em busca dos materiais recicláveis (Figura 01).

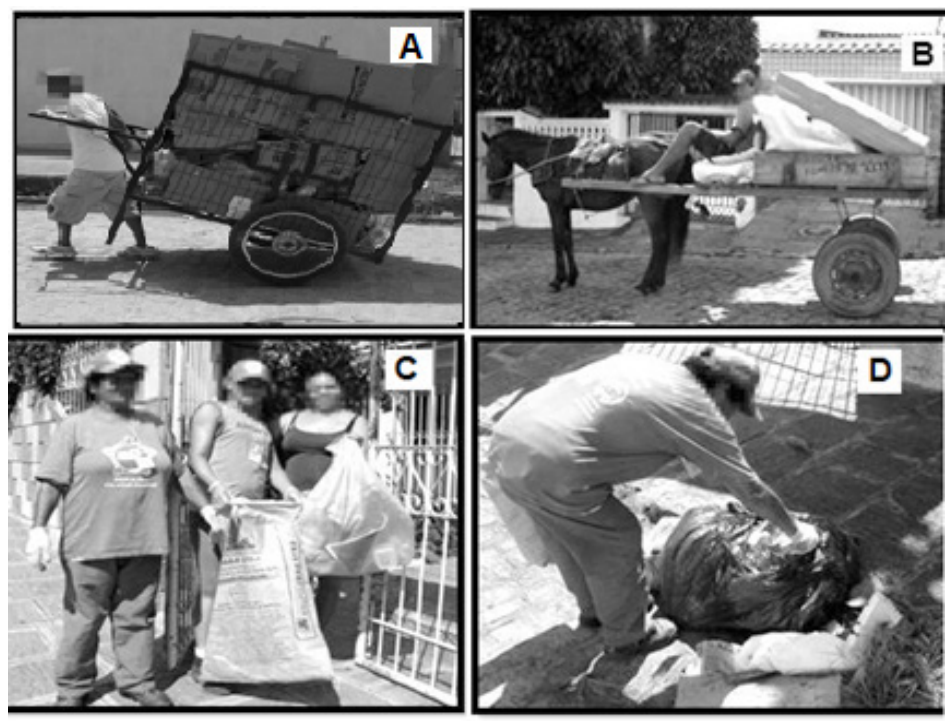

Figura 1 - Catadores e catadoras desempenhando suas funções durante a coleta. Campina Grande, 2011

Em discrepância, os catadores de materiais recicláveis informais fazem sua rotina de trabalho individualmente, não existe diferenciação dos gêneros, tanto os homens quanto as mulheres saem em suas carroças improvisadas de material metálico retirado da "caixa de geladeira" com rodas de bicicleta, das quais se utilizam para buscar materiais recicláveis "soltos" nas ruas (Figura 02).

Silva et al. (2012) descreve que os catadores de materiais recicláveis informais usualmente:

Puxam carrinhos pesados, porém com capacidade para armazenar quantidade mínima de material reciclável, considerando os quilômetros percorridos para recolher material passível de comercializar, no entanto, devido à falta de seleção na fonte geradora, estes perdem o valor comercial, resultando na diminuição da renda dos catadores de materiais recicláveis e no desperdício de matéria e energia. (SILVA et al., 2012) 
O fato da sociedade não enxergar os resíduos sólidos como materiais passíveis da reciclagem ou reutilização torna a coleta seletiva incipiente, dificultamdo, por conseguinte, as atividades dos catadores de materiais recicláveis.

Os catadores de materiais recicláveis informais não apresentam carga horária definida, ultrapassando as oito horas diárias determinadas pelo artigo $7^{\circ}$ da Constituição Federal (BRASIL, 1988) e pelo artigo 58 da Consolidação das Leis do Trabalho-CLT (BRASIL, 1943). Em divergência, os associados à ARENSA cumprem as oito horas diárias de trabalho. A rotina dos catadores de materiais recicláveis informais é exaustiva e precária e pode ultrapassar 12 horas de trabalho (SILVA et al., 2012).

Segundo Velloso (2005), a jornada de trabalho de catadores e catadoras de materiais recicláveis, excessivamente longa e penosa, tem efeitos adversos sobre a saúde, tanto pelo desgaste físico que acarreta quanto pela frequente exposição aos fatores nocivos como as variações climáticas e o contato com vetores de agentes de doenças infecciosas.Somam-se a essas dificuldades as condições de vida e trabalho dos catadores: baixa escolaridade, necessidade de desenvolver diversas atividades para sobreviver e o trabalho sem proteção social (BORTOLI, 2009).

Os catadores de materiais recicláveis associados e informais não fogem à realidade encontrada no restante do Brasil. Verificamos que os catadores de materiais recicláveis informais e associados à ARENSA possuem baixa escolaridade, sendo que a maioria possui o ensino fundamental incompleto (56.3\%), encontram dificuldades na leitura e interpretação de pequenos textos e frases, porém sabem assinar o próprio nome, bem como ler e interpretar os acontecimentos do cotidiano com sabedoria. Como por exemplo: relacionar a crise econômica mundial com as dificuldades do mercado de materiais recicláveis.

O número de catadores e catadoras de materiais recicláveis analfabetos é bastante significativo, sendo que 25,0\% dos associados à ARENSA são analfabetos e 50,0\% dos informais, o que implica de forma negativa diretamente na formalização e profissionalização dos catadores de materiais recicláveis que atuam na informalidade. Sabe-se, pois, o quão burocrático é formalizar um grupo social; as exigências econômicas, educacionais e sociais literalmente não permitem que os catadores de materiais recicláveis informais possam usufruir dos seus direitos. Destacamos que $12,5 \%$ dos catadores de materiais recicláveis informais possuem o ensino médio incompleto, porém não conseguem atuar no mercado de trabalho.

Segundo Carmo (2005), a falta de escolaridade dos catadores corrobora para o desconhecimento dos aspectos que envolvem a logística do processo de reciclagem. Carmo (2005) e Magera (2003) concordam que esse pouco conhecimento do circuito da reciclagem é um forte impedimento para que catadores obtenham ganhos melhores nessa atividade.

Cerca de $75,0 \%$ dos catadores de materiais recicláveis informais possuem um salário mensal que varia entre 80,00 a 150,00 reais. No entanto, 25,0\% dos informais conseguem atingir uma renda mensal de um salário mínimo, somando a renda familiar entre os cônjuges que atuam como catadores de materiais recicláveis.

No período da pesquisa, os catadores de materiais recicláveis associados à ARENSA possuíam uma renda mensal superior aos que vivem na informalidade: média mensal $R \$ 238,00$, diretamente concebida a partir da venda dos materiais recicláveis, pois com a organização do grupo através da mobilização e sensibilização utilizando estratégias em Educação Ambiental (SILVA, 2010; OLIVEIRA et al., 2011; RIBEIRO et al., 2011) as áreas de coleta seletiva aumentaram, e consequentemente, a maior parte dos materiais recicláveis chega aos associados à ARENSA higienizados e segregados, aumentando o seu valor comercial. Também o local de acondicionamento dos resíduos comporta maior quantidade desses materiais. Aqueles que apresentam renda superior a $\mathrm{R} \$ 238,00$ fazem parte de programa de governo ou trabalham esposo e esposa, e em alguns casos, a filha.

A organização da ARENSA em Associação demonstra o fortalecimento e a união desse grupo social, contribuindo para o aumento da renda, favorecendo a coleta seletiva e diminuindo os impactos socioambientais, visto que os resíduos seriam encaminhados ao Lixão do município, única forma de disposição final na época de realização da pesquisa.

De acordo com Gonçalves (2005), apesar de todas as dificuldades do trabalho, sem apoio do poder público e com o preconceito da sociedade, esses trabalhadores, criativamente, conseguem sobreviver e ao mesmo tempo, cuidar do meio ambiente. 
O acondicionamento dos materiais recicláveis coletados pelos catadores de materiais recicláveis associados à ARENSA ocorre em um galpão, localizado no bairro do Catolé, Campina Grande-PB, o aluguel custa $\mathrm{R} \$ 400,00$, pago mensalmente pelos associados, o que caracteriza a independência financeira do grupo neste contexto. Diferentemente, os catadores de materiais recicláveis informais acondicionam e fazem a triagem dos materiais coletados nos quintais e becos de suas residências, ou até mesmo em frente a suas casas, nas calçadas (Figura 02), provocando diversos transtornos à saúde desses profissionais e à comunidade, pois os resíduos sólidos armazenados de forma incorreta atraem macro e microvetores, conforme Ribeiro et al. (2011); Silva et al. (2010); Oliveira et al. (2011).

Em uma das residências dos catadores de materiais recicláveis informais foi observado que os resíduos sólidos eram acondicionados junto com animais domésticos, como galinhas, galos, cachorros, bodes, coelhos, o que potencializa a contaminação dos resíduos, pois, com a falta de higienização dos materiais coletados na fonte geradora, misturados às excretas e fezes dos animais, as chances de haver disseminação de doenças é potencialmente elevada (Figura 02).

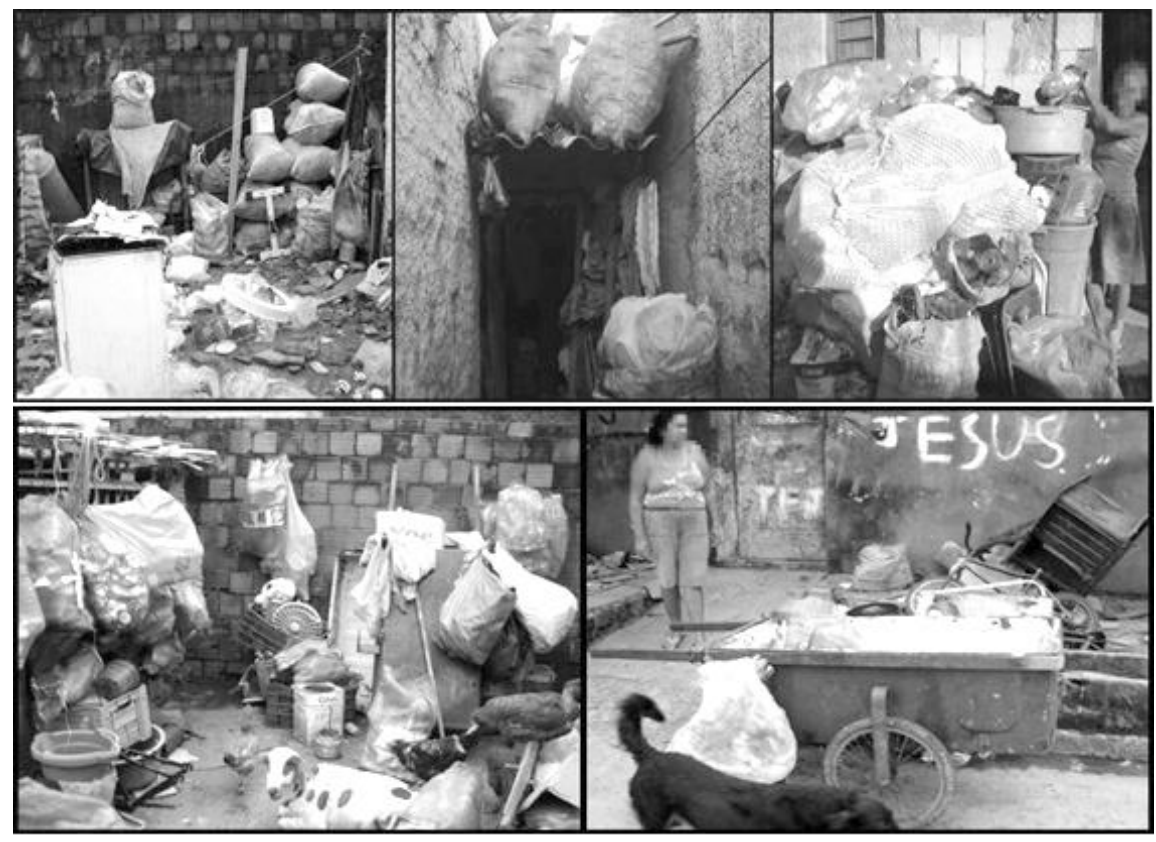

Figura 2 - Acondicionamento e transporte utilizados pelos catadores de materiais recicláveis informais, Campina Grande, 2011

Comparando os catadores de materiais recicláveis que atuam na informalidade com os catadores associados à ARENSA, observamos que estes estão submetidos a condições menos insalubres, como por exemplo, dispõem de um galpão para acondicionamento e triagem dos materiais recicláveis coletados. Nesse local, os resíduos sólidos são separados de acordo com sua respectiva composição: metal, papel e papelão, plástico e vidro e posteriormente, comercializado aos "atravessadores" de Campina Grande - PB. Mesmo que o Galpão ainda não seja o mais adequado, constitui vantagem em relação aos informais, considerando-se a forma de acondicionamento observada.

Segundo Miura (2004), atualmente o problema está em reconhecer o direito do catador às condições dignas de trabalho e de vida, para além da sobrevivência.

De acordo com Medeiros e Macêdo (2006), o catador de material reciclável é exposto a riscos de saúde, a preconceitos sociais e à desregulamentação dos direitos trabalhistas, condições que são extremamente precárias, tanto na informalidade de trabalho quanto na remuneração.

Diariamente os catadores de materiais recicláveis são expostos a diversas situações de riscos, tanto físicas quanto psicológicas, condenando-se a uma sofrível qualidade de vida e riscos à saúde, além de estarem completamente vulneráveis aos preconceitos e racismos criados em torno desta atividade (ALEXANDRINO et al., 2009).

Sabemos que para o catador de material reciclável ter qualidade de vida digna são necessárias, melhores condições de trabalho e saúde. A coleta seletiva mitiga os impactos decorrentes da profissão 
de catadores de material reciclável, pois esses profissionais deveriam receber diariamente os resíduos higienizados e segregados, não requerendo abrir sacolas de porta em porta, tendo contato com resíduos sanitários, orgânicos e perfurocortantes. Além de que a coleta seletiva na fonte geradora pode contribuir de forma expressiva para o aumento da renda salarial mensal, visto que se o material reciclável higienizado apresenta maior valorização econômica.

Quando questionados sobre o conceito de saúde, 37,5\% dos catadores de materiais recicláveis associados à ARENSA atribuem ao ato de trabalhar, 25,0\% afirmam que saúde é o organismo não ter doenças, 25,0\% alegam que está com saúde é ter assistência médica digna no Sistema Único de Saúde e 12,5\% acreditam que a saúde está diretamente relacionada aos hábitos de higiene pessoal e coletivo.

Em relação aos catadores de materiais recicláveis informais, observamos que 37,5\% também atribuem à "saúde" o fato de o organismo estar desprovido de doenças, $12,5 \%$ afirmam que os hábitos de higiene corroboram para uma saúde adequada e 25,0\% acreditam que a saúde do catador de material reciclável está intimamente ligada ao uso dos equipamentos de proteção individual. Possivelmente, pelo fato de $100 \%$ dos catadores informais entrevistados não terem acesso a esse tipo de recurso e aos vários acidentes ocorridos durante as atividades de catação (Tabela 01).

Tabela 1 - Concepção de saúde dos catadores e catadoras de materiais recicláveis associados e informais que atuam no bairro do Tambor, em Campina Grande-PB. 2011

\begin{tabular}{ccccc}
\hline CONCEITO DE & \multicolumn{3}{c}{ Catadores e catadoras de materiais } & \\
SAÚDE & recicláveis (\%) & & Desvpad. \\
\cline { 2 - 5 } & Associados (ARENSA) & Informais & Média & 17,7 \\
Assistência médica & 25,0 & 0,0 & 12,5 & 8,8 \\
Ausência de & 25,0 & 37,5 & 31,3 & 0,0 \\
doenças & 12,5 & 12,5 & 12,5 & 26,5 \\
Higiene & 37,5 & 0,0 & 12,5 & 17,7 \\
Trabalhar & 0,0 & 25 & 12,5 & 8,8 \\
Utilizar EPIs & 0,0 & 12,5 & 6,3 & 8,8 \\
Religião & 0,0 & 12,5 & 6,3 & \\
Não sabe & & &
\end{tabular}

Desvpad.: Desvio Padrão

A Organização Mundial de Saúde (OMS) reconhece a saúde não apenas como a ausência de doença, mas como a situação de perfeito bem-estar físico, mental e social. Essa definição, até avançada para a época em que foi realizada, é, no momento, irreal, ultrapassada e unilateral (SEGRE; FERRAZ, 1997).

O conceito de saúde reflete a conjuntura social, econômica, política e cultural, ou seja, saúde não representa a mesma coisa para todas as pessoas, dependerá da época, do lugar, da classe social, de valores individuais, de concepções científicas, religiosas, filosóficas (SCLIAR, 2007).

Sabemos que o simples fato de separar o resíduo seco do úmido impede diferentes tipos de impactos negativos, como a contaminação dos materiais recicláveis pelo resíduo sólido orgânico, que através do processo anaeróbico produz o chorume e gases tóxicos, o que não garante, todavia, condições de saúde plena, haja vista que outros fatores devem ser considerados, a exemplo das condições de moradia, de alimentação, autoestima e educação.

A segregação dos materiais recicláveis na fonte geradora é de imensa importância para que os catadores de materiais recicláveis possam ter condições de trabalho mais dignas e menos insalubres. Observamos que, entre os associados, $62,5 \%$ das residências que doam materiais recicláveis a esses profissionais segregaram o material. Em discrepância, $62,5 \%$ dos informais afirmam não haver essa segregação na fonte geradora, havendo necessidade de coletar os materiais recicláveis no mesmo período que o carro coletor municipal faz as coletas nas residências, para abrir as sacolas de resíduos dispostas em frente às residências, onde geralmente os materiais encontram-se todos misturados.

São inúmeras as dificuldades encontradas no exercício da profissão catador de material reciclável. Entre os organizados em associação, as dificuldades mais citadas foram: 1) transporte inadequado 
$(12,5 \%)$; 2) Excesso de peso nos carrinhos durante a coleta $(25,0 \%) ; 3)$ Mudanças na temperatura ambiental (12,5\%); 4) Separação dos resíduos no Galpão - Triagem (37,5\%), os associados consideram esta etapa a mais difícil a ser realizada, visto que na fonte geradora os materiais recicláveis são separados apenas como resíduo seco e resíduo molhado, o primeiro são os resíduos que são aproveitados pelos catadores de materiais recicláveis, como as garrafas PET, embalagens de vidro, latinhas de alumínio, dentre outros; e os resíduos molhados são também conhecidos como resíduos sólidos orgânicos, os quais não são aproveitados pelos catadores.

Entre os catadores de materiais recicláveis informais, os principais problemas citados foram: 1) Transporte inadequado (12,5\%); 2) Desprezo social (12,5\%), uma vez que a população não os enxergam enquanto profissionais, tratando-os muitas vezes como marginais. 3) Triagem dos resíduos (12,5\%); 4) $\mathrm{E}$, a grande maioria (62,5\%), afirmaram não encontrar nenhuma dificuldade no exercício profissional, isso nos mostra, que esses profissionais não enxergam a própria realidade.

Os riscos que a profissão catador de material reciclável proporciona diariamente são inúmeros: contato com vidros quebrados, resíduos sólidos de serviço de saúde, como seringas e agulhas que podem ou não está infectadas, contaminação com o resíduo sólido orgânico e resíduo sanitário, dentre outros.

Os cortes com vidros caracterizam o acidente mais comum entre trabalhadores da coleta domiciliar, das esteiras de catação nas cooperativas de reciclagem, e também entre os catadores e catadoras dos vazadouros de lixo (VIRGEM, 2010). Outros objetos pontiagudos como espinhos, pregos, agulhas de seringas e espetos são também responsáveis por corriqueiros acidentes envolvendo trabalhadores.

Nos grupos estudados, os principais acidentes ocupacionais citados foram: 1) Cortes com vidros (Associados - 50,0\%; Informais - 37,5\%), isso se deve ao fato de muitos moradores ainda misturarem esse tipo de material reciclável aos demais, como plásticos, papéis e metais, não possuindo um cuidado especial com esse tipo de material; 2) Arranhões de pequeno a grande porte (Associação - 12,5\%; Informais - 12,5\%); 3) Perfurações com pregos (Associação - 12,5\%), sendo o agravante desde tipo de material é que se enferrujado e contaminado com a bactéria do tétano.

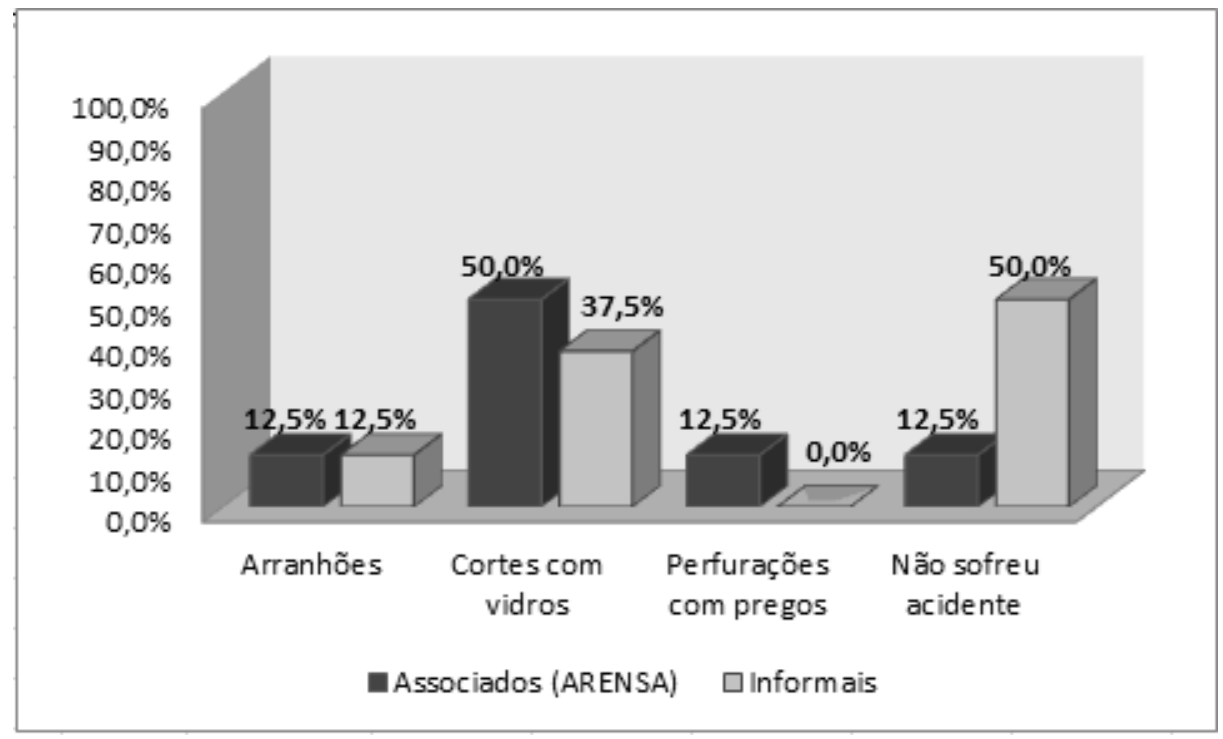

Figura 3 - Acidentes citados pelos catadores de materiais recicláveis associados e informais durante o exercício profissional, em Campina Grande-PB. 2011

O uso de equipamentos de proteção individual (EPI) é recomendado para proteger os trabalhadores do contato com agentes infecciosos, tóxicos ou corrosivos, calor excessivo, fogo e outros perigos. São exemplos de EPI para a separação dos resíduos em cooperativas e ou associações: luvas, uniforme, avental impermeável, óculos de proteção, máscaras e botas impermeáveis (VIRGEM, 2010).

Os acidentes nesse tipo de trabalho geralmente acontecem em decorrência da precarização e falta de condições adequadas de trabalho, traduzidos em ferimentos e perdas de membros por atropelamentos, inalação de gases tóxicos, manejo de materiais perfurocortantes, prensagem em equipamentos de compactação e veículos automotores, além de mordidas de animais (cães, ratos) e picadas de insetos 
(FERREIRA; ANJOS, 2001).

A exposição de catadores de materiais recicláveis aos riscos de acidentes de trabalho geralmente são provocados pela ausência de Educação Ambiental, pela falta de condições adequadas de trabalho, pelos riscos de contaminação pelo contato direto, com maiores probabilidades da presença ativa de microrganismos infecciosos (VELLOSO, 2005; FERREIRA; ANJOS, 2001).

A carga física de trabalho em condições insalubres, sem o uso de equipamentos de proteção individual (EPIs) e com rotinas de trabalho que apresentam riscos resultam na perda da saúde do trabalhador, o que acarreta a redução da sua capacidade laboral e, por conseguinte, de seu rendimento (MOURA, 2010).

Segundo a Portaria n ${ }^{\circ} 3.214$ do Ministério do Trabalho Brasileiro (BRASIL, 1978) em sua Norma Regulamentadora $n^{\circ} 6$, considera-se Equipamento de Proteção Individual - EPI, todo dispositivo ou produto, de uso individual utilizado pelo trabalhador, destinado à proteção de riscos suscetíveis de ameaçar a segurança e a saúde no trabalho.

Observamos que a maioria dos catadores de materiais recicláveis não utiliza os EPIs. O número é crescente entre os catadores de materiais recicláveis informais, visto que $87,5 \%$ afirmaram não utilizar nenhum equipamento de proteção, o que reflete as condições financeiras desse grupo e o desconhecimento dos riscos que os resíduos sólidos podem trazer para sua saúde (Figura 04A). Em relação aos organizados em associação, diferentemente do grupo citado anteriormente, 75,0\% utilizam EPIs como bonés, botas e luvas (Figura 04B).
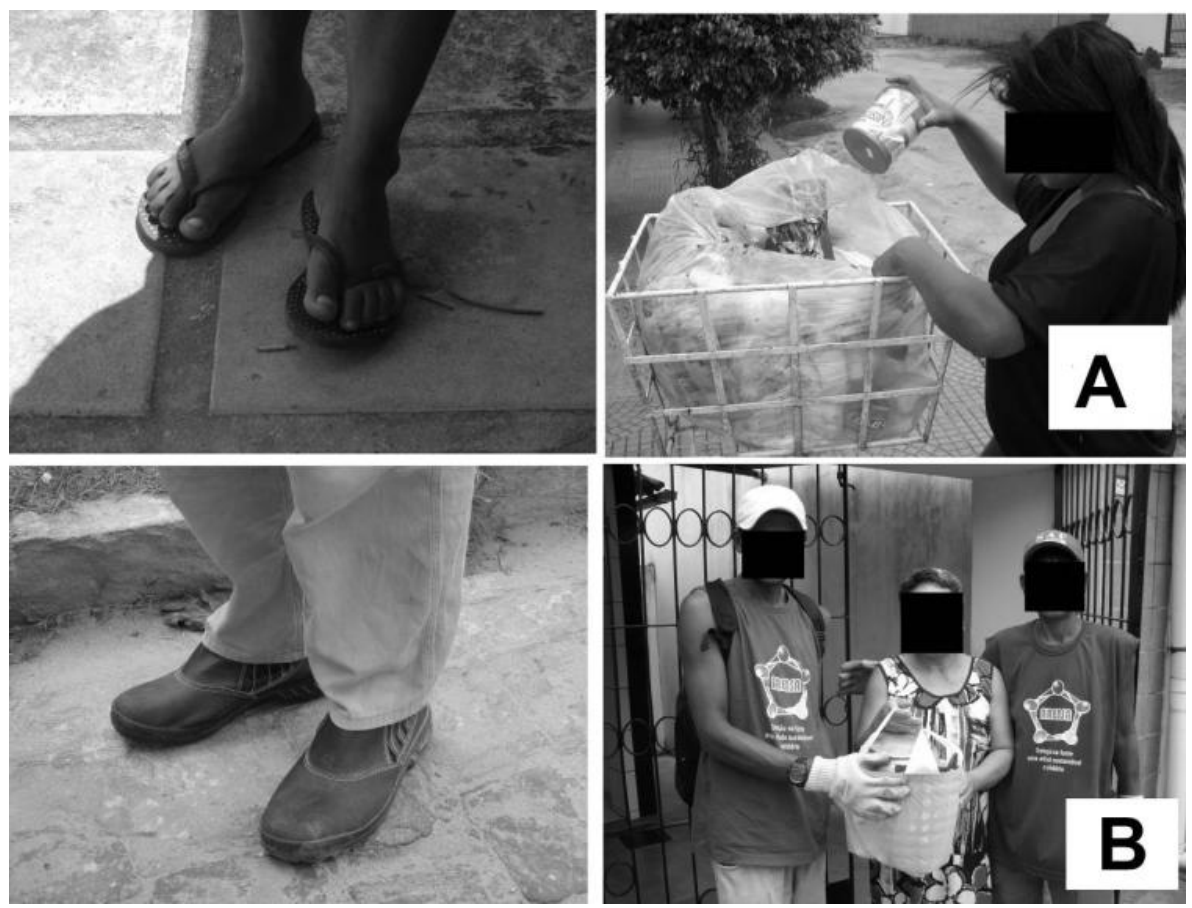

Figura 4 - Utilização dos Equipamentos de Proteção Individual pelos catadores e catadoras de materiais recicláveis associados (A) e informais (B), em Campina Grande-PB. 2011

A carga física de trabalho em condições insalubres, sem o uso de equipamentos de proteção individual (EPIs) e com rotinas de trabalho que apresentam riscos resulta na perda da saúde do trabalhador, o que acarreta a redução da sua capacidade laboral e, por conseguinte, de seu rendimento (MOURA, 2010)

Os catadores e catadoras de materiais recicláveis tornam-se profissionais expostos aos riscos ocupacionais e ambientais em decorrência da atividade insalubre que exercem, no trato com os resíduos sólidos, estando sujeitos à contaminação pela inalação, à manipulação de material contaminado, perfurocortante, aos produtos químicos, à carga excessiva de trabalho e à exposição às variações climáticas.

Portanto, podemos afirmar através dos dados observados que os catadores de materiais recicláveis associados à ARENSA possuem condições de trabalho menos insalubres do que aqueles que 
atuam na informalidade no Bairro do Tambor, em Campina Grande-PB.

\section{CONCLUSÕES}

Observamos que as condições insalubres às quais estão submetidos os catadores de materiais recicláveis informais oferecem riscos para a saúde desses profissionais, principalmente no que diz respeito à coleta dos materiais recicláveis nas residências, onde os resíduos se encontram misturados aos resíduos orgânicos, sanitários e também, em alguns casos, aos resíduos sólidos de serviço de saúde. Outro problema diagnosticado é a forma de acondicionamento e triagem dos materiais recicláveis coletados pelos catadores informais, que ocorre nos quintais das suas residências.

As condições em que estão imersos os associados à ARENSA, por sua vez propiciam melhor qualidade de vida, pois a organização em Associação desse grupo social contribui de forma significativa para a coleta seletiva nos bairros de atuação desses profissionais. Consequentemente, uma parte dos materiais recicláveis recebida da fonte geradora pelos associados à ARENSA encontra-se separada e higienizada, o que confere menos riscos de acidentes e de contração de doenças aos associados. No entanto, os riscos não foram totalmente eliminados, haja vista que as condições de triagem e de armazenamento ainda são precárias. Somado ao longo percurso percorrido pelos associados diariamente (média de $18 \mathrm{Km}$ ), puxando um carrinho pesado (média de $98 \mathrm{Kg}$ ), independentemente das condições climáticas e submetidos à violência social. Ressalta-se que a renda mensal dos associados ainda não favorece a alimentação adequada para suportar o gasto exigido de energia.

Constatamos ainda que a organização de catadores de materiais recicláveis colaborou de forma significativa para a melhoria nas condições de saúde desses trabalhadores e de sua família, minimizando impactos socioambientais e motivarando a construção de conhecimento na área ambiental, além de favorecer a coleta seletiva nos bairros de atuação do grupo, cerca de 500 residências em 11 bairros na cidade de Campina Grande - PB.

A organização de catadores de materiais recicláveis favoreceu de forma significativa as condições de saúde desses trabalhadores e de sua família, minimizando impactos socioambientais, além de favorecer a coleta seletiva nos bairros de atuação do grupo.

Portanto, há influência na organização de catadores de materiais recicláveis em associação para a melhoria da saúde e minimização dos impactos socioambientais, embora no momento desta pesquisa a influência percebida expressasse pequenos avanços em decorrência do pouco tempo de formalização.

\section{REFERÊNCIAS}

ALBIZU, E.J. Diretrizes para um centro de triagem de materiais recicláveis quanto ao ambiente construído em relação à segurança e saúde no trabalho: um estudo de caso no Guarituba, município de Piraquara, região metropolitana de Curitiba. Curitiba: UFPR, 2008. 215 p. Dissertação de Mestrado (Pós-Graduação em Construção Civil do Setor de Tecnologia). Universidade Federal do Paraná, Curitiba, 2008.

ALBIZU, E.J.; LIMA, C.A.; PIASKOWY, P. Segurança e Saúde do Trabalho do Catador de Material Reciclável. Anais. XIV Seminário Sul-Brasileiro da ANAMT. Curitiba - PR, 2008. Curitiba: 26 a 29 de novembro de 2008.

ALENCAR, M.C.B.; CARDOSO, C.C.O.; ANTUNES, M.C. Condições de trabalho e sintomas relacionados à saúde de catadores e catadoras de materiais recicláveis em Curitiba. Revista de Terapia Ocupacional da Universidade de São Paulo, v. 20, n. 1, p. 36-42, jan./abr. 2009.

ALEXANDRINO, D. F. L; FERREIRA, M. E. C.; LIMA, C. L.; MAKKAI, L. F. C. Proposta de inclusão social e melhoria da qualidade de vida e saúde dos catadores e catadoras de materiais recicláveis de Viçosa - MG através da atividade física. Fit Perf J.,v. 8, n. 2, p. 115-22, mar/abr. 2009.

AVELAR, S. A. Avaliação do Sistema de Gerenciamento de Resíduos Sólidos Urbanos do Município de Coronel Fabriciano - Minas Gerais. Minas Gerais: UNEC, 2006. 113 p. Dissertação de Mestrado (Programa 
de Pós-graduação Meio Ambiente e Sustentabilidade). Centro Universitário de Caratinga, Minas Gerais, 2006.

BRASIL, Constituição da República Federativa do Brasil. Artigo 7º. Brasília, 1988.

BRASIL, Consolidação das Leis do Trabalho-CLT. Artigo 58. Lei 5.452. Brasília, 1943.

BRASIL, 2010. Instituto Brasileiro de Geografia e Estatística-IBGE. Disponível em: < http://www.censo2010. ibge.gov.br/dados_divulgados/index.php?uf=25> Acesso em: 30 nov. 2010.

BRASIL, Ministério do Meio Ambiente. 4a Conferência Nacional do Meio Ambiente. Disponível em: <http:// www.conferenciameioambiente.gov.br/a-4a-cnma/geracao-de-emprego-e-renda/>. Acesso em 01 ago. 2013

BRASIL, Normas Regulamentadoras de Segurança e Saúde no Trabalho. Portaria do Ministério do Trabalho Brasileiro ${ }^{\circ}$ 3.214. Brasília 1978.

BOFF, L. Civilização planetária. Rio de Janeiro: Sextante, 2003. 132p.

BOFF, L. Saber cuidar. In: A Falta de Cuidado: estigma do nosso tempo. São Paulo, Vozes, 1999.p. 17-29.

CAVALCANTE, L.P.S.; SOUSA, R.T.M.; MAIA, H.J.L.; RIBEIRO, L.A.; SILVA, M.M.P. Impactos positivos decorrentes do processo de sensibilização, formação e mobilização de catadores e catadoras de materiais recicláveis deum bairro de Campina Grande - PB, de 2008 a 2012. Anais. III Congresso Brasileiro de Gestão Ambiental. Goiânia - GO, 2012.

CARMO, M.S. A semântica "negativa" do lixo como fator "positivo" à sobrevivência da Catação - Estudo de caso sobre a associação dos recicladores do Rio de Janeiro. Anais.EncontroNacional da Associação Nacional de Pós-graduação em Pesquisaem Administração. ENANPAD, Brasília - DF. 2005.

CEMPRE. Compromisso Empresarial para Reciclagem: Política Nacional de Resíduos Sólidos Agora é LeiNovos Desafios para Poder Público, Empresas, Catadores e catadoras e População. 2010. Disponível em: <http://www.cempre.org.br/download/pnrs_002.pdf> Acesso em: 10 jan. 2013.

DALL'AGNOL, C.M.; FERNANDES, F.S. Health and self-care among garbage collectors: work experiences in a recyclable garbage cooperative. Revista Latino-americana de Enfermagem, n. 15, p. 729-735, set/out. 2007.

FERREIRA, J. A.; ANJOS, L. A. Aspectos de saúde coletiva e ocupacional associados à gestão dos resíduos sólidos municipais. Cadernos de Saúde Pública, v. 17, n. 3, p. 689-696, mai/ jun. 2001.

FILARDI, F.; SIQUEIRA, E.S.; BINOTTO, E. Os catadores e catadoras de resíduos e a responsabilidade socioambiental: a percepção sobre seu lugar social. Revista de Gestão Social e Ambiental, v.5, n. 3, p. 17-35, set./ dez. 2011.

GONÇALVES, R. C. M. A voz dos catadores de lixo em sua luta pela sobrevivência. Fortaleza: UECE, 2005. 134 p. Dissertação de Mestrado (Programa de Pós-graduação em Políticas Públicas e Sociedade). Universidade Estadual do Ceará, Fortaleza, 2005.

LEFF, E. Epistemologia Ambiental. São Paulo: Cortez, 2006.

GOUVEIA, N. Resíduos sólidos urbanos: impactos socioambientais e perspectiva de manejo sustentável com inclusão social. Revista Ciência \& Saúde Coletiva, v. 17, n. 6, p. 1503-1510, 2012.

LIPP, M. E. N. (Org). Pesquisas sobre stress no Brasil: saúde, ocupações e grupos de risco. São Paulo: Ed. Papirus, 1996. 
MAGERA, M. Os empresários do lixo: um paradoxo da modernidade. Campinas, SP: Editora Átomo, 2003.

MARRAS, W. S. Occupation al low back disorder causation and control. Ergonomics, v. 43, n. 7, p. 880-902, 2000.

MEDEIROS, L. F. R.; MACÊDO, K. B. Catador de material reciclável: uma profissão para além da sobrevivência? Revista Psicologia e Sociedade, v. 18, n. 2, p. 62-71, maio/ ago. 2006.

MIURA, P. C. O. Tornar-se catador: uma análise psicossocial. São Paulo: PUC, 2004. 164 p. Dissertação de Mestrado. Pontifícia Universidade Católica de São Paulo, São Paulo, 2004.

MOURA, A.A.S.B.F. Riscos ambientais à saúde ocupacional do catador de recicláveis em Goiânia. Goiânia: PUC, 2010. 139 p. Dissertação de Mestrado (Programa de Pós-Graduação em Ciências Ambientais e Saúde). Pontifícia Universidade Católica de Goiás, 2010.

OLIVEIRA, A.G.; SILVA, M.M.P.; RIBEIRO, L.A.; CAVALCANTE, L.P.S.; LEITE, V. D. Perfil de Catadores e Catadoras de Materiais Recicláveis que atuam em Campina Grande-PB. Anais. $26^{\circ}$ Congresso Brasileiro de Engenharia Sanitária e Ambiental. ABES, Porto Alegre - RS. 2011.

PORTO, M. F. Saúde do Trabalhador e o desafio ambiental: contribuições do enfoque ecossocial, da ecologiapolítica e do movimento pela justiça ambiental. Ciência e Saúde Coletiva. v. 10, n. 4, p. 1-11, out/dez. 2005.

PORTO, M. F. S.; JUNCÁ, D. C. M.; GONÇALVES, R. S.; FILHOTE, M. I. F. Lixo, trabalho e saúde: um estudo de caso com catadores e catadoras em um aterro metropolitano no Rio de Janeiro, Brasil. Caderno de Saúde Pública, v. 20, n. 6, p. 1503-1514, nov/ dez. 2004.

RIBEIRO, L. A.; SILVA, M.M.P.; LEITE, V. D.; SILVA, H. Educação ambiental como instrumento de organização de catadores de materiais recicláveis na Comunidade Nossa Senhora Aparecida, Campina Grande-PB. Revista de Biologia e Farmácia, v. 5, n. 2, p. 59-72, 2011.

SCLIAR, M. História do Conceito de Saúde. Revista Saúde Coletiva, v. 17, n. 1, p. 29-41. 2007.

SEGRE, M.; FERRAZ, F.C. O conceito de saúde. Revista Saúde Pública, v. 31, n. 5, p. 538-542. Oct. 1997.

SIQUEIRA, M. M.; MORAES, M. S. Saúde coletiva, resíduos sólidos urbanos e os catadores e catadoras de lixo. Revista Ciência e Saúde Coletiva, v. 14, n. 6, p. 2115-2122, dez/ jan. 2009.

SILVA, M.M.P.; LEITE, V.D.; CAVALCANTE, L.P.S.; CLEMENTINO, A.S.G.; OLIVEIRA, A.G. Educação Ambiental para organização e reconhecimento de catadores e catadoras de materiais recicláveis em Campina Grande-PB; estratégia para gestão integrada de resíduos sólidos. Anais. V Semana de Extensão da UEPB: Desenvolvimento Regional, Políticas Públicas e Identidades, Campina Grande-PB, 2010.

SILVA, M. M. P.; LEITE, V. D. Estratégias para realização de educação ambiental emescolas do ensino fundamental. Revista Eletrônica do Mestrado em Educação Ambiental, v. 20, p. 1-21, jan/jun. 2008.

SILVA, M.M.P.; RIBEIRO, L.A.; CAVALCANTE, L.P.S.; OLIVEIRA, A.G.; SOUSA, R.T.M.; OLIVEIRA, J.V. Quando Educação Ambiental faz a diferença, vidas são transformadas. Revista Eletrônica do Mestrado em Educação Ambiental, v. 28, p. 388-402, jan/jun. 2012.

SOBRAL, N. G.; SANTIAGO, I. M. F. L.; COSTA, J. C. Gênero e invisibilidade socialentre catadores de materiais recicláveis de Campina Grande - PB. In: II Seminário Nacional: Gênero e práticas culturais - culturas, leituras e representações. Anais. João Pessoa - PB - Brasil, 28 a 30 de outubro de 2009.

VELLOSO, M.P. Os catadores e catadoras de lixo e o processo de emancipação social. Revista Ciência e saúde coletiva; v.10, p. 49-56, 2005. 
VIEIRA, M.H.M.; SOFA, R.F; BARBA, I.S. Perfil Socioeconômico dos Selecionadores e Coletores de Materiais Recicláveis de Naviraí-MS: Subsídios para Políticas Publicas. Anais. XI Encontro Anual de Iniciação Científica da Universidade Estadual de Maringá/Pró-Reitoria de Pesquisa e Pós-Graduação. Maringá-PR: 2002.

VIRGEM, M.R.C. Estudo dos riscos ocupacionais e percepções dos separadores de resíduos cooperados sobre o trabalho e a preservação ambiental. Aracaju: UNIT, 2010. 84 p. Dissertação de Mestrado (Programa de Pósgraduação em Saúde e Ambiente). Universidade Tiradentes, Aracaju, 2010.

THIOLLENT, Michael. Metodologia da pesquisa ação. $16^{a}$ ed. São Paulo: Cortez, 2008, 132p. 